\title{
Revealing factors hindering halal certification in East Kalimantan Indonesia
}

\begin{abstract}
Purpose: This study aims to explore various factors that hamper halal certification in food service industries in East Kalimantan, Indonesia. World halal business as well as awareness in halal products and services consumption has been growing rapidly for the past few years. However, many industry players have not yet realized those huge potential concepts of halal business. Food service industries such as restaurants and caterings show less concern in putting priority on the issue of halal certification.

Design/methodology/approach: A qualitative data collection technique called nominal group technique (NGT) was used in this study. Four categories of stakeholders participated in this NGT to represent certifying body, consumers, industry player and government. Each category was given a fundamental question: ñWhat factors are hindering restaurant and catering in East Kalimantan, Indonesia, in obtaining halal certification?ò

Findings: The authors found that through NGT, the authors can obtain top priority issues to be followed up by the respecting institutions which are concerned. The lack of socialization and information have led to the lack of knowledge and awareness. This is the most important issue addressed by the participants.

Research limitations/implications: This research was conducted to collect data from various stakeholders in East Kalimantan Province of Indonesia. Considering the vast expanse of Indonesia and different level of development in each province, results of this study could not be generalized as Indonesia situation in general.
\end{abstract}

Keyword: Indonesia; Restaurant; Halal; Food catering service; Hindering factors; NGT 